\title{
A multimodal intervention to improve hand hygiene compliance in peripheral wards of a tertiary care university centre: a cluster randomised controlled trial
}

Seven Johannes Sam Aghdassi ${ }^{1,2^{*}}$ (D) Christin Schröder ${ }^{1,2}$, Elke Lemke ${ }^{1,2}$, Michael Behnke $e^{1,2}$, Patricia Manuela Fliss ${ }^{3}$, Carolin Plotzki ${ }^{3}$, Janina Wenk ${ }^{3}$, Petra Gastmeier ${ }^{1,2}$ and Tobias Siegfried Kramer ${ }^{1,2,4}$

\begin{abstract}
Background: Interventions to improve hand hygiene $(\mathrm{HH})$ compliance are a key element in the practice infection prevention and control. It was our objective to assess the effect of a multimodal intervention on $\mathrm{HH}$ compliance at a tertiary care university hospital. As a secondary objective, we investigated the effect of the intervention on the occurrence of device-associated bloodstream infections.

Methods: We performed a single centre cluster randomised controlled trial at a university hospital in Germany. Twenty peripheral wards were invited to participate and randomly assigned to either the intervention $(n=10)$ or control group $(n=10)$. Quarterly, specifically trained student employees conducted direct compliance observations in all twenty wards. The intervention entailed dissemination of teaching materials on aseptic procedures, equipment with flexibly mountable alcoholic hand rub dispensers, and quarterly feedback on $\mathrm{HH}$ compliance.

Results: In total, 21,424 HH opportunities were observed. Overall, compliance did not change significantly in either group (intervention group: 59\% vs. 61\% (1482 HH actions for $2494 \mathrm{HH}$ opportunities vs. $5033 \mathrm{HH}$ actions for $8215 \mathrm{HH}$ opportunities), odds ratio (OR) 1.08 (95\% confidence interval (Cl95) 0.88, 1.33)); control group: 59\% vs. 60\% (1457 HH actions for $2484 \mathrm{HH}$ opportunities vs. $4948 \mathrm{HH}$ actions for $8231 \mathrm{HH}$ opportunities), OR 1.06 (Cl95 0.84, 1.35)). Compliance prior to aseptic procedures improved significantly in the intervention group from $44 \%$ ( $168 \mathrm{HH}$ actions for $380 \mathrm{HH}$ opportunities) to 53\% (764 HH actions for $1452 \mathrm{HH}$ opportunities) (OR 1.40 (Cl95 1.04, 1.89), $p=0.03$ ), while no significant increase was noted in the control group. In the intervention group, significantly fewer device-associated bloodstream infections per 1000 patient-days occurred than in the control group ( 84 vs. 123, incidence rate ratio 0.61 (Cl95 0.46, 0.81), $p<0.01)$.

\footnotetext{
*Correspondence: seven-johannes-sam.aghdassi@charite.de

${ }^{1}$ Charité - Universitätsmedizin Berlin, corporate member of Freie Universität Berlin, Humboldt-Universität zu Berlin, and Berlin Institute of Health, Institute of Hygiene and Environmental Medicine, Berlin, Germany

${ }^{2}$ National Reference Centre for Surveillance of Nosocomial Infections, Berlin, Germany

Full list of author information is available at the end of the article
}

(c) The Author(s). 2020 Open Access This article is licensed under a Creative Commons Attribution 4.0 International License, which permits use, sharing, adaptation, distribution and reproduction in any medium or format, as long as you give appropriate credit to the original author(s) and the source, provide a link to the Creative Commons licence, and indicate if changes were made. The images or other third party material in this article are included in the article's Creative Commons licence, unless indicated otherwise in a credit line to the material. If material is not included in the article's Creative Commons licence and your intended use is not permitted by statutory regulation or exceeds the permitted use, you will need to obtain permission directly from the copyright holder. To view a copy of this licence, visit http://creativecommons.org/licenses/by/4.0/ The Creative Commons Public Domain Dedication waiver (http://creativecommons.org/publicdomain/zero/1.0/) applies to the data made available in this article, unless otherwise stated in a credit line to the data. 
(Continued from previous page)

Conclusions: The lack of a significant overall improvement of $\mathrm{HH}$ compliance demonstrated that comprehensive implementation of $\mathrm{HH}$ interventions in multiple wards simultaneously is difficult. However, through targeted intervention measures, we were able to significantly increase $\mathrm{HH}$ compliance before aseptic procedures.

Keywords: Hand hygiene, Multimodal intervention, Randomised controlled trial, Infection prevention, Nonintensive care ward

\section{Background}

Hand hygiene $(\mathrm{HH})$ is one of the most effective measures to prevent healthcare-associated infections (HAIs) and transmission of multidrug-resistant pathogens [1-3]. The implementation of a multimodal strategy as recommended by the $\mathrm{WHO}$, can effectively increase $\mathrm{HH}$ compliance and thereby reduce HAIs [4-6]. Implementation of such strategies has been promoted by the German national clean care is safer care campaign ("Aktion Saubere Hände") for numerous years [7]. Despite these efforts, recent data from the German national $\mathrm{HH}$ surveillance network shows a considerable potential for improvement [8]. This especially applies to $\mathrm{HH}$ compliance prior to aseptic procedures, which is lower when compared to the other moments [9]. Existing evidence suggests that additional performance feedback and goal setting are effective ways to achieve improved HH compliance [10-15].

We hypothesised that an intensified multimodal intervention (i.e. improving knowledge on $\mathrm{HH}$, dissemination of teaching materials for aseptic procedures, improved accessibility of alcoholic hand rub dispensers at point of care), with the addition of quarterly direct $\mathrm{HH}$ observation and feedback would improve $\mathrm{HH}$ compliance, and correlate with lower rates of bloodstream infections (BSIs), as well as positive blood cultures overall. We decided to test our hypotheses in a cluster randomised study setting. The stated objectives pertained to the cluster level.

\section{Methods}

\section{Study design and randomisation}

Interventions to promote $\mathrm{HH}$ on intensive care units have been conducted at our hospital in the past. On non-intensive care (i.e. peripheral) wards of our hospital, interventions as performed in this trial have not been undertaken previously. We therefore decided to perform a cluster randomised controlled trial in 20 peripheral wards of the Charité-University Medicine hospital in Berlin, a large tertiary care university hospital with three separate sites and approximately 3000 beds. Each participating ward represented a cluster.

In the process of ward selection, we decided to exclude palliative and paediatric wards for ethical reasons. Moreover, intermediate care units were excluded. Since one of our objectives was to assess the effect of the intervention on the incidence of positive blood cultures (see below), we decided to exclude wards with low blood culture sampling frequencies. To achieve that, we evaluated the blood culture sampling frequency of all nonintensive care wards in the year 2016. Wards with a number of blood cultures per 1000 patient-days above the median were included in the randomisation. Of these wards, 20 were randomly selected and allocated to either group (intervention: $n=10$; control: $n=10$ ) with a computer-generated sequence (https://www.randomizer. org/). The randomisation was performed by the study coordinators. Participation of wards was on a voluntary basis. The decision for or against participation was made by the head nurse and physician of the respective ward. Recruitment of wards was performed between September and November 2017. All wards were free to end their participation in the study at any stage without stating a reason. The study was approved by the ethics commission of Charité-University Medicine Berlin (EA4/ 123/17).

\section{Description of the intervention}

The intervention of this study consisted of three aspects. First, quarterly interdisciplinary team meetings of ward staff with the study team including data on $\mathrm{HH}$ compliance observations, and goal setting. Second, distribution of training materials (see description below), and third, distribution of flexibly mountable alcoholic hand rub dispensers. The selection of the individual elements of the intervention was done in alignment with available literature $[10-13,16]$. These intervention measures were undertaken and provided solely for wards of the intervention group, not the control group. The intervention period was from the beginning of January 2018 until the end of December 2018.

\section{Hand hygiene compliance observations}

After randomisation of wards, 5 cycles of $\mathrm{HH}$ compliance observations according to the recommendations of the WHO [17], were performed in all 20 wards. The first cycle was performed in December 2017 and served as a baseline assessment against which the effects of the intervention were measured. The following 4 cycles were performed quarterly over the intervention period of 1 year. A minimum of 150 observations with a minimum of 30 observations before clean or aseptic procedure per 
cycle was required. While staff in control wards received no feedback on $\mathrm{HH}$ observation data, wards in the intervention group received regular feedback on compliance data. The feedback was embedded in interdisciplinary team meetings, where the study team presented results of the compliance observations that were then discussed with the ward staff.

$\mathrm{HH}$ compliance observations were executed by student employees, which were trained in $\mathrm{HH}$ observation methodology by experienced local infection control staff in a specifically organised workshop. Observations were recorded using the Observe app from HARTMANN. In order to increase the quality of observations, the student employees were supervised by an experienced infection control nurse.

\section{Intervention materials}

Wards randomised into the intervention group were introduced to the intervention during a "kick-off meeting" (i.e. feedback on the first cycle of $\mathrm{HH}$ compliance observation), where they received materials to promote $\mathrm{HH}$ and infection prevention that had been developed by the study team prior to the study. Wards were encouraged during the kick-off meeting and following quarterly team meetings, as well as by email reminders, to implement these materials into their routine patient care. Among the materials were 10 step-by-step pictogram checklists for selected aseptic procedures, two explanatory films, and flexibly mountable alcoholic hand rub dispensers. The materials were chosen based on the fact that $\mathrm{HH}$ is an integral part of many aseptic procedures in routine patient care.

The 10 step-by-step checklists addressed the following topics:

- insertion of peripheral venous catheters (PVCs)

- use of a sterile extension set for PVCs

- management (incl. dressing change) of PVCs

- management (incl. dressing change) of central venous catheters (CVCs)

- management of central venous ports

- preparation of intravenous injections

- application of intravenous injections

- preparation of intravenous infusions

- application of intravenous infusions

- disconnection of intravenous infusions

The two animated explanatory films contained additional information on the insertion of PVCs, and preparation as well as handling of intravenous infusions. All intervention materials were handed out during the kickoff meeting, where applicable, both in printed and electronic form.

\section{Observed outcomes}

As our primary outcome, we selected $\mathrm{HH}$ compliance of healthcare workers in participating wards. Compliance was determined by direct observations following the WHO Five Moments of Hand Hygiene model [18].

As a secondary outcome, we selected the incidence of device-associated BSIs for which prospective surveillance was conducted over a 12 months period (11 months during the intervention period, 1 month post-intervention). Due to technical difficulties, only 19 of the 20 participating wards were included in this part of the study. BSIs were defined as a blood culture with a recognised pathogen, or two positive blood cultures with a common skin contaminant, drawn at least $48 \mathrm{~h}$ after admission. The two positive blood cultures with a common skin contaminant had to be from two separate blood samples within a five-day period. BSIs were considered as deviceassociated, if an intravenous catheter was present either on the day of sampling, or the day before in case the catheter was removed on the day of sampling. Furthermore, the catheter had to be in place for a minimum of 3 days before the sample was taken. Where more than one catheter fulfilled the criteria for a device-associated $\mathrm{BSI}$, an association was made to the catheter being inserted in the larger blood vessel (e.g. CVC was chosen over PVC), except where local signs of infection indicated otherwise. Information to make this allocation was gathered from the ward staff, primarily the treating physicians.

Additionally, we evaluated the frequency of positive blood cultures taken at least $48 \mathrm{~h}$ after admission of the patient to the ward. For this, all positive blood culture sets of all 20 wards were collected for a one-year baseline period, the one-year intervention period, and a three-month follow-up period. Isolated microorganisms from blood cultures were divided into nine categories: coagulase-negative staphylococci, Staphylococcus aureus, Streptococcus spp., Enterococcus spp., Enterobacteriales, non-fermenting bacteria, Candida albicans, other Candida spp., and others.

All observed outcomes pertained to the cluster level.

\section{Statistical analysis}

$\mathrm{HH}$ compliance was calculated for every group (control vs. intervention) and every cycle. $\mathrm{HH}$ opportunities and actions were analysed descriptively. To compare the baseline period (cycle 1) with the intervention period (cycles 2-5), the absolute change in compliance was calculated. Additionally, odds ratios (ORs) were calculated with a generalised linear mixed effect model including ward as a random effect. To minimise the potential distortion by confounders and investigate the effect of the intervention on $\mathrm{HH}$ compliance more accurately, a multivariable logistic regression analysis was conducted, 
taking into account other known factors of influence [4, $9,14,19]$. For this purpose, ORs and 95\% confidence intervals (CI95) were calculated. Parameters included in the model were: period (baseline vs. intervention), professional group, WHO-moment, and ward specialty.

Mean infection rates per 1000 patient-days were calculated with CI95 and mid $p$-values. To compare isolates per patient-days between baseline, intervention, and follow-up periods, incidence rates and incidence rate ratios (IRRs) with CI95 and mid $p$-values were calculated. Incidence rates were calculated as Poisson rates. CI95 and $p$-values for IRRs were calculated by medianunbiased estimation. A $p$-value of less than 0.05 was considered significant. All analyses were performed with SAS and R [20]. Graphics were done with ggplot2 [21].

\section{Results}

All 20 wards initially enrolled in the study participated for the full duration. Table S1 in the online supplement (Additional file 1) summarises structural characteristics of the 10 wards in the intervention group and 10 wards in the control group.

Overall, 21,424 HH opportunities and 12,920 HH actions were observed. Figure 1 illustrates the compliance per measurement cycle as well as the underlying number of $\mathrm{HH}$ opportunities and actions, separately for the intervention and control group. While both groups showed fluctuations in $\mathrm{HH}$ compliance over time, median compliance in both groups was higher in cycle 5 than in the baseline measurement (cycle 1). An overall slight increase in $\mathrm{HH}$ compliance was also noted when comparing compliance of cycle 1 (baseline period) to aggregated compliance of cycle 2-5 (intervention period). Stratification by the different WHO-moments yielded diverse results. Through further stratifying the indication "before clean or aseptic procedure" by procedure, we were able to detect an increase in compliance before intravascular catheter manipulation (45\% vs. $55 \%)$ and before contact with mucous membrane ( $47 \%$ vs. $57 \%$ ) in the intervention group. In the control group, we observed an increase in compliance before preparation of intravenous medication ( $42 \%$ vs. $66 \%$ ) (Table S2 in the online supplement (Additional file 1)).

While no significant change over time was observed in either group for the overall $\mathrm{HH}$ compliance, we observed a significant increase in compliance for the indication "before clean or aseptic procedure" in the intervention group (44\% (168 HH actions for $380 \mathrm{HH}$ opportunities) vs. $53 \%$ (764 $\mathrm{HH}$ actions for $1452 \mathrm{HH}$ opportunities), OR 1.40 (CI95 1.04, 1.89), $p=0.03$ ). Although changes were noted with regard to other WHO-moments, these failed to reach statistical significance (Table 1).

To identify factors that had a significant influence on $\mathrm{HH}$ compliance, we performed a multivariable logistic regression analysis for the outcome compliant performance of $\mathrm{HH}$. To determine the effect of the intervention, compliance in the intervention period was compared separately for the two study groups to compliance of the baseline measurement. While the intervention period was not revealed to have a significant effect in either of the two study groups, the profession of the healthcare worker and the WHO-moment both had a significant

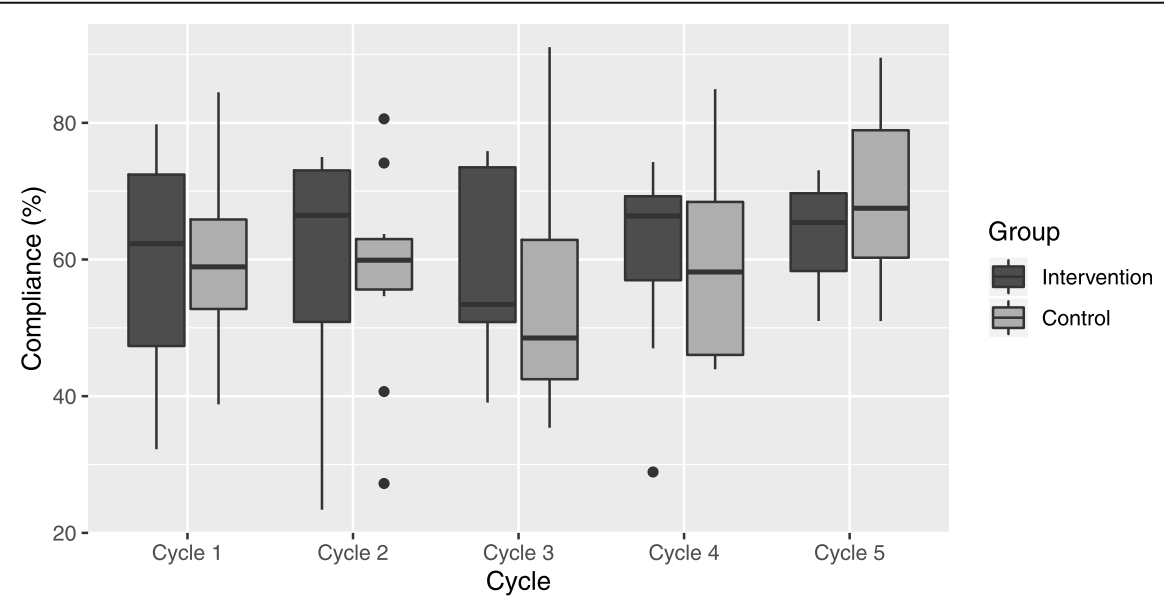

\begin{tabular}{r|c|c|c|c|c|c|c|c|c|c|}
\hline & Intervent & Control & Intervent & Control & Intervent & Control & Intervent & Control & Intervent & Control \\
\hline opportunities & 2494 & 2484 & 2076 & 2090 & 2118 & 2086 & 2011 & 2012 & 2010 & 2043 \\
\hline actions & 1482 & 1457 & 1255 & 1195 & 1264 & 1118 & 1226 & 1204 & 1288 & 1431 \\
\hline
\end{tabular}

Fig. 1 Boxplots of hand hygiene compliance per measurement cycle by study group. The table under the graph lists the number of hand hygiene opportunities and actions per cycle by study group 
Table 1 Change in hand hygiene compliance per indication by study group and by study period

\begin{tabular}{|c|c|c|c|c|c|c|c|}
\hline WHO-moment & Group & Period & $\begin{array}{l}\text { Number of } \mathrm{HH}- \\
\text { opportunities }\end{array}$ & $\begin{array}{l}\text { Number of } \mathrm{HH}- \\
\text { actions }\end{array}$ & $\begin{array}{l}\text { Compliance } \\
(\%)\end{array}$ & $\begin{array}{l}\text { Absolute } \\
\text { change }\end{array}$ & $\begin{array}{l}\text { Odds ratio } \\
\text { (CI95), } \boldsymbol{p} \text {-value }\end{array}$ \\
\hline \multirow[t]{4}{*}{$\overline{\text { All }}$} & \multirow[t]{2}{*}{ Intervention } & Baseline & 2494 & 1482 & 59.42 & & reference \\
\hline & & Intervention & 8215 & 5033 & 61.27 & 1.85 & $\begin{array}{l}1.08(0.88,1.33), \\
0.46\end{array}$ \\
\hline & \multirow[t]{2}{*}{ Control } & Baseline & 2484 & 1457 & 58.66 & & reference \\
\hline & & Intervention & 8231 & 4948 & 60.11 & 1.45 & $\begin{array}{l}1.06(0.84,1.35), \\
0.62\end{array}$ \\
\hline \multirow[t]{4}{*}{1 - before touching a patient } & \multirow[t]{2}{*}{ Intervention } & Baseline & 698 & 393 & 56.3 & & reference \\
\hline & & Intervention & 2346 & 1408 & 60.02 & 3.72 & $\begin{array}{l}1.16(0.86,1.58), \\
0.33\end{array}$ \\
\hline & \multirow[t]{2}{*}{ Control } & Baseline & 658 & 352 & 53.5 & & reference \\
\hline & & Intervention & 2130 & 1201 & 56.38 & 2.88 & $\begin{array}{l}1.12(0.80,1.58), \\
0.50\end{array}$ \\
\hline \multirow{4}{*}{$\begin{array}{l}2 \text { - before clean or aseptic } \\
\text { procedure }\end{array}$} & \multirow[t]{2}{*}{ Intervention } & Baseline & 380 & 168 & 44.21 & & reference \\
\hline & & Intervention & 1452 & 764 & 52.62 & 8.41 & $\begin{array}{l}1.40(1.04,1.89), \\
0.03\end{array}$ \\
\hline & \multirow[t]{2}{*}{ Control } & Baseline & 426 & 193 & 45.31 & & reference \\
\hline & & Intervention & 1738 & 905 & 52.07 & 6.76 & $\begin{array}{l}1.31(0.93,1.84) \\
0.12\end{array}$ \\
\hline \multirow{4}{*}{$\begin{array}{l}3 \text { - after body fluid exposure } \\
\text { risk }\end{array}$} & \multirow[t]{2}{*}{ Intervention } & Baseline & 171 & 114 & 66.67 & & reference \\
\hline & & Intervention & 527 & 333 & 63.19 & -3.48 & $\begin{array}{l}0.86(0.60,1.23), \\
0.40\end{array}$ \\
\hline & \multirow[t]{2}{*}{ Control } & Baseline & 241 & 145 & 60.17 & & reference \\
\hline & & Intervention & 705 & 482 & 68.37 & 8.20 & $\begin{array}{l}1.43(0.94,2.18), \\
0.09\end{array}$ \\
\hline \multirow[t]{4}{*}{4 - after touching a patient } & \multirow[t]{2}{*}{ Intervention } & Baseline & 791 & 563 & 71.18 & & reference \\
\hline & & Intervention & 2496 & 1774 & 71.07 & -0.11 & $\begin{array}{l}1.00(0.77,1.29) \\
0.97\end{array}$ \\
\hline & \multirow[t]{2}{*}{ Control } & Baseline & 668 & 499 & 74.7 & & reference \\
\hline & & Intervention & 2414 & 1685 & 69.8 & -4.90 & $\begin{array}{l}0.78(0.56,1.09), \\
0.15\end{array}$ \\
\hline \multirow{4}{*}{$\begin{array}{l}5 \text { - after touching patient } \\
\text { surroundings }\end{array}$} & \multirow[t]{2}{*}{ Intervention } & Baseline & 454 & 244 & 53.74 & & reference \\
\hline & & Intervention & 1394 & 754 & 54.09 & 0.35 & $\begin{array}{l}1.01(0.81,1.27), \\
0.90\end{array}$ \\
\hline & \multirow[t]{2}{*}{ Control } & Baseline & 491 & 268 & 54.58 & & reference \\
\hline & & Intervention & 1244 & 675 & 54.26 & -0.32 & $\begin{array}{l}0.99(0.76,1.28), \\
0.92\end{array}$ \\
\hline
\end{tabular}

Abbreviations: $\mathrm{HH}$ hand hygiene, $\mathrm{Cl} 95$ 95\% confidence interval; ${ }^{a}$ result of logistic regression with ward as a cluster effect

effect on the outcome. The professional group "others" (i.e. non-nursing, non-physician staff) were associated with significantly lower $\mathrm{HH}$ compliance. The WHOmoment "after touching a patient" was associated with significantly higher compliance when compared to other WHO-moments (Table 2).

Comparison of device-associated BSIs showed that significantly fewer infections per 1000 patient-days occurred in the intervention group versus the control group (84 vs. 123, IRR 0.61 (CI95 0.46, 0.81), $p<0.01$ ). When stratifying infections by device, no significant differences were found for PVCs or central venous ports.
However, significantly fewer CVC-associated BSIs per 1000 patient-days occurred in the intervention group than control group (36 vs. 75, IRR 0.43 (CI95 0.29, 0.64), $p<0.01$ ) (Table 3).

A separate analysis of positive blood cultures taken at least $48 \mathrm{~h}$ after admission showed a significantly higher occurrence of positive isolates per 1000 patient-days in the control group during the intervention period versus the baseline period (297 vs. 226, IRR 1.28 (CI95 1.08, 1.53), $p<0.01$ ). We did not observe a similar significant change in the intervention group with regard to the study period (Table 4). Data for positive blood cultures 
Table 2 Multivariable logistic regression model for the outcome compliant hand hygiene

\begin{tabular}{|c|c|c|c|}
\hline Parameter & Characteristic & $\begin{array}{l}\text { Odds ratio } \\
\text { (Cl95) }\end{array}$ & $\boldsymbol{p}$-value \\
\hline \multirow[t]{4}{*}{ Period } & Baseline (intervention group) & reference & \\
\hline & Baseline (control group) & $0.92(0.53,1.59)$ & 0.75 \\
\hline & Intervention (intervention group) & $1.09(0.87,1.36)$ & 0.44 \\
\hline & Intervention (control group) & $0.97(0.53,1.78)$ & 0.93 \\
\hline \multirow[t]{3}{*}{ Professional group } & Physicians & reference & \\
\hline & Others & $0.51(0.32,0.81)$ & $<0.01$ \\
\hline & Nurses & $0.99(0.79,1.24)$ & 0.93 \\
\hline \multirow[t]{5}{*}{ WHO-moment } & 4 - after touching a patient & reference & \\
\hline & 1 - before touching a patient & $0.55(0.46,0.67)$ & $<0.01$ \\
\hline & 2 - before clean or aseptic procedure & $0.41(0.30,0.57)$ & $<0.01$ \\
\hline & 3 - after body fluid exposure risk & $0.77(0.60,0.99)$ & 0.04 \\
\hline & 5 - after touching patient surroundings & $0.53(0.44,0.63)$ & $<0.01$ \\
\hline \multirow[t]{2}{*}{ Unit specialty } & Medical & reference & \\
\hline & Surgical & $1.16(0.68,1.99)$ & 0.58 \\
\hline
\end{tabular}

Abbreviations: C195 95\% confidence interval; ${ }^{a}$ result of logistic regression with ward as a cluster effect

separated by pathogen or pathogen-group are illustrated in Table S3 in the online supplement (Additional file 1).

\section{Discussion}

Overall, compliance of healthcare workers to the WHO Five Moments of Hand Hygiene improved in both arms of our study. This increase was not statistically significant and lower than in reports from other randomised controlled trials [14, 22, 23]. A similar study by Stewardson et al., observed a larger overall increase in $\mathrm{HH}$ compliance in the different groups of their trial, even with a higher initial baseline compliance than in our study [13]. More in alignment with our results, Fuller et al. observed improved HH compliance in intensive care units, but not in peripheral units [10]. Despite our centre's long lasting participation in the national clean care is safer care campaign and successful history of implementation of multimodal strategies for infection prevention, direct observations of compliance had not been performed in most of the participating wards prior to this study. However, some wards independently continued the practice of quarterly direct compliance observation and feedback after the end of the trial. We consider this an important achievement underscoring the relevance of a sense of ownership among healthcare workers in any intervention designed to increase patient safety in a sustainable manner.

Despite only a marginal increase in overall $\mathrm{HH}$ compliance, we observed a significant improvement of compliance before aseptic procedures in the intervention

Table 3 Device-associated bloodstream infections per 1000 patient-days by study group

\begin{tabular}{|c|c|c|c|c|c|}
\hline \multirow[t]{2}{*}{ Device } & \multicolumn{2}{|c|}{ Intervention group } & \multicolumn{2}{|c|}{ Control group } & \multirow[b]{2}{*}{ IRR (C195), $\boldsymbol{p}$-value } \\
\hline & $\begin{array}{l}\text { Number of } \\
\text { BSIs }\end{array}$ & $\begin{array}{l}\text { Mean rate/1000 patient-days } \\
\text { (Cl95) }\end{array}$ & $\begin{array}{l}\text { Number of } \\
\text { BSIs }\end{array}$ & $\begin{array}{l}\text { Mean rate/1000 patient-days } \\
\text { (CI95) }\end{array}$ & \\
\hline All & 84 & $0.71(0.57,0.88)$ & 123 & $1.16(0.96,1.38)$ & $\begin{array}{l}0.61(0.46,0.81),< \\
0.01\end{array}$ \\
\hline $\begin{array}{l}\text { Peripheral venous } \\
\text { catheter }\end{array}$ & 10 & $0.08(0.04,0.16)$ & 11 & $0.10(0.05,0.19)$ & $0.82(0.34,1.96), 0.65$ \\
\hline Central venous port & 20 & $0.17(0.10,0.26)$ & 21 & $0.20(0.12,0.30)$ & $0.86(0.46,1.59), 0.62$ \\
\hline Central venous catheter & 36 & $0.31(0.21,0.42)$ & 75 & $0.71(0.56,0.89)$ & $\begin{array}{l}0.43(0.29,0.64),< \\
0.01\end{array}$ \\
\hline Other & 18 & $0.15(0.09,0.24)$ & 16 & $0.15(0.09,0.24)$ & $1.01(0.51,2.01), 0.97$ \\
\hline
\end{tabular}


Table 4 Positive blood cultures per 1000 patient-days by study group and by study period

\begin{tabular}{|c|c|c|c|c|c|c|c|c|c|}
\hline \multirow[t]{2}{*}{ Study group } & \multicolumn{2}{|c|}{ Baseline period } & \multicolumn{2}{|c|}{ Intervention period } & \multicolumn{2}{|c|}{ Follow-up period } & \multicolumn{3}{|l|}{ Comparison } \\
\hline & $\begin{array}{l}\text { Number } \\
\text { of isolates }\end{array}$ & $\begin{array}{l}\text { Mean rate/ } 1000 \\
\text { patient-days (Cl95) }\end{array}$ & $\begin{array}{l}\text { Number } \\
\text { of isolates }\end{array}$ & $\begin{array}{l}\text { Mean rate/ } 1000 \\
\text { patient-days (Cl95) }\end{array}$ & $\begin{array}{l}\text { Number } \\
\text { of isolates }\end{array}$ & $\begin{array}{l}\text { Mean rate/ } 1000 \\
\text { patient-days (Cl95) }\end{array}$ & $\begin{array}{l}\text { IRR (C195), } \\
\boldsymbol{p} \text {-value } \\
\text { Intervention } \\
\text { vs. Baseline }\end{array}$ & $\begin{array}{l}\text { IRR (CI95), } \\
\boldsymbol{p} \text {-value } \\
\text { Follow- } \\
\text { up vs. } \\
\text { Baseline }\end{array}$ & $\begin{array}{l}\text { IRR (Cl95), } \\
\boldsymbol{p} \text {-value } \\
\text { Follow-up } \\
\text { vs. } \\
\text { Intervention }\end{array}$ \\
\hline $\begin{array}{l}\text { Intervention } \\
\text { group }\end{array}$ & 161 & $1.42(1.21,1.66)$ & 172 & $1.46(1.25,1.70)$ & 53 & $1.78(1.33,2.32)$ & $\begin{array}{l}1.03(0.83 \\
1.27), 0.80\end{array}$ & $\begin{array}{l}1.25(0.91 \\
1.69), 0.17\end{array}$ & $\begin{array}{l}1.22(0.88 \\
1.64), 0.22\end{array}$ \\
\hline $\begin{array}{l}\text { Control } \\
\text { group }\end{array}$ & 226 & $1.98(1.73,2.26)$ & 297 & $2.54(2.26,2.85)$ & 59 & $2.08(1.58,2.68)$ & $\begin{array}{l}1.28(1.08 \\
1.53),<0.01\end{array}$ & $\begin{array}{l}1.05(0.78 \\
1.39), 0.74\end{array}$ & $\begin{array}{l}0.82(0.61 \\
1.07), 0.15\end{array}$ \\
\hline
\end{tabular}

Abbreviations: IRR incidence rate ratio, C195 95\% confidence interval

group, while compliance for this moment improved in the control group as well, but not significantly. This is especially relevant, since the teaching materials provided as part of our intervention strategy primarily focused on this moment. A decision, which was made in reaction to the known low compliance before aseptic procedures [24]. Previous randomised controlled trials have not placed a similar focus on $\mathrm{HH}$ compliance before aseptic procedures. The fact that there was no long-term follow-up to our intervention, however, renders it difficult to estimate the sustainability of the observed positive effects. Whether these will persist and whether the improvement in $\mathrm{HH}$ compliance, and particularly in $\mathrm{HH}$ compliance before aseptic procedures, will be longlasting, remains to a certain extent speculative.

Multivariable logistic regression revealed that compliance was highly dependent on the type of moment and the profession of the healthcare worker. Compliance "after touching a patient" was higher than for any other moment. These findings correspond to finding of other international and national publications $[5,6,8]$. In alignment with other publicised studies, non-nursing, non-physician staff ("others") showed significantly lower compliance $[5,8]$. Underlying reasons for this phenomenon might be the heterogeneity of this professional group and worse accessibility of training and education on the matter. Multivariable analysis did not identify the period "intervention" as a factor with a significant effect on $\mathrm{HH}$ compliance. This missing effect could either be explained by inadequacy of the intervention measures, or insufficient uptake of the intervention by ward staff. Unstructured qualitative feedback from wards and observations made by the study team during the quarterly feedback meetings rather suggested a perceived lack of ownership by ward staff. This may have resulted in an insufficient uptake and implementation of intervention measures by the ward staff (e.g. infrequent use of teaching materials), illustrating the difficulty of establishing an effective intervention in multiple wards simultaneously. The importance of a sense of ownership and enhanced leadership regarding $\mathrm{HH}$ have been demonstrated in earlier publications $[25,26]$.

We observed significantly lower rates of deviceassociated BSIs in the intervention group when compared to the control group, similar to other studies that have demonstrated a reduction in HAI rates due to improved HH [27-29]. Despite a focus on PVCs in our teaching materials, this difference was mainly due to a lower rate of CVC-associated BSIs. This observation may be attributable to differences in patient population and frequency of CVC-usage. However, since we did not record device-days in the included wards during the study period, this explanation remains speculative. Overall, low rates of PVC-associated BSIs were recorded, reiterating findings from a previous study on the matter at our centre [30].

As an additional finding, we observed that pathogens identified from blood cultures, regardless of whether device-associated or not, significantly increased in the control group during the intervention period when compared to the baseline period. A similar trend was not observed in the intervention group, which can be interpreted as a positive effect of the intervention. Regarding the pathogens obtained from positive blood cultures, no significant changes were observed concerning the most frequently occurring pathogens. Explanations for this result, however, remain speculative, given the overall low number of positive blood cultures per pathogen or pathogen-group.

Various limitations have to be acknowledged when interpreting the data. The direct observations of $\mathrm{HH}$ performed in this study only represent a fraction of all $\mathrm{HH}$ opportunities and actions performed in wards during the study period. Baseline compliance was established in a single measurement and was therefore prone to potential random effects. Observed shifts in compliance could have set in before the start of the intervention (i.e. between baseline measurement and "kick-off meeting"). Furthermore, the study design did not include a long-term follow-up regarding $\mathrm{HH}$ compliance. 
Therefore, it remains speculative whether observed effects of the intervention were sustainable or not. With regard to potential confounders, it has to be recognised that "cross contamination", for instance distribution of intervention materials from intervention to control wards was possible, and that the observation itself may have already contributed to improved $\mathrm{HH}$ compliance ("Hawthorne effect") in all wards (incl. Control wards). To minimise these potential confounders, observers did not give feedback to healthcare workers during the observations, and all personnel in the intervention wards were asked to not further distribute any of the provided materials for the duration of the study. Another potential confounder was due to the fact that the primary observers were a heterogeneous group of students who had limited pre-existing knowledge about $\mathrm{HH}$ and compliance observation. To address this and increase the robustness of our data, all primary observers were trained in accordance with the WHO $\mathrm{HH}$ observation methodology, supervised by an experienced infection control nurse, and steadily assigned to certain wards.

We have no standardised information on how intervention materials were used in the day-to-day routine work of the intervention wards, making it difficult to estimate their effect. Furthermore, rotations and changes in ward staffing, as well as changes in equipment used by wards (e.g. different types of catheters used over time) could represent a confounding factor.

For outcome parameters relating to BSIs, definitions used for device-associated BSIs were not evaluated against established surveillance definitions, since no clinical data on patients, such as fever or other indicators of infection, were systematically collected. Therefore, it is possible that we overestimated BSI-rates. We tried to account for this by including the opinion of the treating physicians in our surveillance. Furthermore, no baseline measurement before the onset of the intervention was available for device-associated BSIs. Consequently, regarding this parameter, solely comparisons between the groups, but not over time, were possible.

\section{Conclusions}

In conclusion, a statistically significant increase in $\mathrm{HH}$ compliance prior to aseptic procedures was observed only for wards in the intervention group. Rates of device-associated BSIs as a surrogate for clinically relevant and preventable infections were significantly lower in the intervention group. These findings illustrate an effect of our intervention. However, the lack of a significant overall increase in $\mathrm{HH}$ compliance underlines the difficulty of our attempt to establish an effective multimodal intervention in multiple wards simultaneously. Future studies will be required to focus on the barriers of implementation and novel approaches to increase $\mathrm{HH}$ compliance, especially outside the intensive care setting.

\section{Supplementary information}

Supplementary information accompanies this paper at https://doi.org/10. 1186/s13756-020-00776-9.

\section{Additional file 1.}

\section{Abbreviations}

$\mathrm{HH}$ : Hand hygiene; HAl: Healthcare-associated infection; BSI: Bloodstream infection; PVC: Peripheral venous catheter; CVC: Central venous catheter; OR: Odds ratio; C195: 95\% confidence interval; IRR: Incidence rate ratio

\section{Acknowledgments}

We would like to thank all participating wards for their efforts during the trial.

\section{Authors' contributions}

S. Aghdassi, P. Gastmeier and T. Kramer defined the study design. S. Aghdassi and T. Kramer developed the intervention materials with the input of P. Fliss, C. Plotzki and J. Wenk. C. Schröder conducted the statistical analyses with the input of S. Aghdassi and T. Kramer. M. Behnke provided the programming necessary for data management. E. Lemke played an important role in the data collection throughout the study. S. Aghdassi drafted the manuscript with the input of P. Gastmeier and T. Kramer. The authors read and approved the final manuscript.

\section{Funding}

BODE Chemie GmbH, a company of the HARTMANN group, funded the trial. The funder helped in designing the intervention materials. The funder had no role in the study design, data management, analyses, interpretation and writing of the manuscript and its submission for publication.

\section{Availability of data and materials}

The datasets used and/or analysed during the current study are available from the corresponding author on reasonable request.

\section{Ethics approval and consent to participate}

The study was approved by the ethics commission of Charité-University Medicine Berlin (EA4/123/17).

\section{Consent for publication}

Not applicable.

\section{Competing interests}

This trial was investigator initiated. BODE Chemie $\mathrm{GmbH}$, a company of the HARTMANN group, funded the trial. S. Aghdassi, C. Schröder, E. Lemke, M. Behnke, P. Gastmeier and T. Kramer declare no further conflicts of interest. C. Plotzki and J. Wenk are employees of BODE Chemie GmbH. Throughout the study, P. Fliss was an employee of BODE Chemie $\mathrm{GmbH}$.

\section{Author details}

${ }^{1}$ Charité - Universitätsmedizin Berlin, corporate member of Freie Universität Berlin, Humboldt-Universität zu Berlin, and Berlin Institute of Health, Institute of Hygiene and Environmental Medicine, Berlin, Germany. ${ }^{2}$ National Reference Centre for Surveillance of Nosocomial Infections, Berlin, Germany. ${ }^{3}$ BODE SCIENCE CENTER, BODE Chemie GmbH, Hamburg, Germany. ${ }^{4}$ Aktion Saubere Hände, Berlin, Germany.

Received: 31 January 2020 Accepted: 9 July 2020

Published online: 18 July 2020

\section{References}

1. Allegranzi B, Pittet D. Role of hand hygiene in healthcare-associated infection prevention. J Hosp Infect. 2009;73:305-15.

2. Pittet D, Allegranzi B, Sax H, Dharan S, Pessoa-Silva CL, Donaldson L, Boyce $J M$, et al. Evidence-based model for hand transmission during patient care and the role of improved practices. Lancet Infect Dis. 2006;6:641-52. 
3. Barnes SL, Morgan DJ, Harris AD, Carling PC, Thom KA. Preventing the transmission of multidrug-resistant organisms: modeling the relative importance of hand hygiene and environmental cleaning interventions. Infect Control Hosp Epidemiol. 2014;35:1156-62.

4. Pittet D, Hugonnet S, Harbarth S, Mourouga P, Sauvan V, Touveneau S, et al. Effectiveness of a hospital-wide programme to improve compliance with hand hygiene. Infection Control Programme. Lancet. 2000;356:1307-12.

5. Grayson ML, Stewardson AJ, Russo PL, Ryan KE, Olsen KL, Havers SM, et al. Effects of the Australian National Hand Hygiene Initiative after 8 years on infection control practices, health-care worker education, and clinical outcomes: a longitudinal study. Lancet Infect Dis. 2018;18:1269-77.

6. Allegranzi B, Gayet-Ageron A, Damani N, Bengaly L, McLaws ML, Moro ML, et al. Global implementation of WHO's multimodal strategy for improvement of hand hygiene: a quasi-experimental study. Lancet Infect Dis. 2013;13:843-51.

7. Wetzker W, Walter J, Bunte-Schonberger K, Schwab F, Behnke M, Gastmeier $P$, et al. Hand rub consumption has almost doubled in 132 German hospitals over 9 years. Infect Control Hosp Epidemiol. 2017;38:870-2.

8. Wetzker W, Bunte-Schonberger K, Walter J, Pilarski G, Gastmeier P, Reichardt C. Compliance with hand hygiene: reference data from the national hand hygiene campaign in Germany. J Hosp Infect. 2016;92:328-31.

9. Kramer T, Walter J, Bunte K, Grajcar R, Clausmeyer J, Emrich J et al. Compliance to the 5 moments of hand hygiene in German hospitals: data from the national surveillance system (HAND-KISS). 29th European Congress of Clinical Microbiology \& Infectious Diseases, abstract P2654. https://www. escmid.org/escmid_publications/escmid_elibrary/material/?mid=69450. Accessed 29 Jan 2020

10. Fuller C, Michie S, Savage J, McAteer J, Besser S, Charlett A, et al. The feedback intervention trial (FIT)--improving hand-hygiene compliance in UK healthcare workers: a stepped wedge cluster randomised controlled trial. PLoS One. 2012;7:e41617.

11. Gould DJ, Moralejo D, Drey N, Chudleigh JH, Taljaard M. Interventions to improve hand hygiene compliance in patient care. Cochrane Database Syst Rev. 2017:9:CD005186

12. Ivers N, Jamtvedt G, Flottorp S, Young JM, Odgaard-Jensen J, French SD, et al. Audit and feedback: effects on professional practice and healthcare outcomes. Cochrane Database Syst Rev. 2012;13:CD000259.

13. Stewardson AJ, Sax H, Gayet-Ageron A, Touveneau S, Longtin Y, Zingg W, et al. Enhanced performance feedback and patient participation to improve hand hygiene compliance of health-care workers in the setting of established multimodal promotion: a single-Centre, cluster randomised controlled trial. Lancet Infect Dis. 2016;16:1345-55.

14. von Lengerke T, Lutze B, Krauth C, Lange K, Stahmeyer JT, Chaberny IF. Promoting hand hygiene compliance. Dtsch Arztebl Int. 2017;114:29-36.

15. Martin-Madrazo C, Soto-Diaz S, Canada-Dorado A, Salinero-Fort MA, MedinaFernandez M. Carrillo de Santa Pau E, et al. cluster randomized trial to evaluate the effect of a multimodal hand hygiene improvement strategy in primary care. Infect Control Hosp Epidemiol. 2012;33(7):681-8.

16. Kirk J, Kendall A, Marx JF, Pincock T, Young E, Hughes JM, et al. Point of care hand hygiene-where's the rub? A survey of US and Canadian health care workers' knowledge, attitudes, and practices. Am J Infect Control. 2016; 44(10):1095-101.

17. Sax H, Allegranzi B, Chraiti MN, Boyce J, Larson E, Pittet D. The World Health Organization hand hygiene observation method. Am J Infect Control. 2009; 37:827-34.

18. Sax H, Allegranzi B, Uckay I, Larson E, Boyce J, Pittet D. 'My five moments for hand hygiene': a user-centred design approach to understand, train monitor and report hand hygiene. J Hosp Infect. 2007;67:9-21.

19. Azim S, Juergens C, McLaws ML. An average hand hygiene day for nurses and physicians: the burden is not equal. Am J Infect Control. 2016;44(7): 777-81

20. R: A Language and Environment for Statistical Computing [computer program]. R Foundation for Statistical Computing; 2019.

21. Wickham H. ggplot2: Elegant Graphics for Data Analysis. New York: Springer-Verlag; 2016.

22. Mertz D, Dafoe N, Walter SD, Brazil K, Loeb M. Effect of a multifaceted intervention on adherence to hand hygiene among healthcare workers: a cluster-randomized trial. Infect Control Hosp Epidemiol. 2010;31:1170-6.

23. Santosaningsih D, Erikawati D, Santoso S, Noorhamdani N, Ratridewi I, Candradikusuma D, et al. Intervening with healthcare workers' hand hygiene compliance, knowledge, and perception in a limited-resource hospital in Indonesia: a randomized controlled trial study. Antimicrob Resist Infect Control. 2017:6:23.

24. Woodard JA, Leekha S, Jackson SS, Thom KA. Beyond entry and exit: hand hygiene at the bedside. Am J Infect Control. 2019:47:487-91.

25. Huis A, Schoonhoven L, Grol R, Donders R, Hulscher M, van Achterberg T. Impact of a team and leaders-directed strategy to improve nurses' adherence to hand hygiene guidelines: a cluster randomised trial. Int J Nurs Stud. 2013;50(4):464-74.

26. Huis A, Hulscher M, Adang E, Grol R, van Achterberg T, Schoonhoven L. Cost-effectiveness of a team and leaders-directed strategy to improve nurses' adherence to hand hygiene guidelines: a cluster randomised trial. Int J Nurs Stud. 2013;50(4):518-26.

27. Kirkland KB, Homa KA, Lasky RA, Ptak JA, Taylor EA, Splaine ME. Impact of a hospital-wide hand hygiene initiative on healthcare-associated infections: results of an interrupted time series. BMJ Qual Saf. 2012;21:1019-26.

28. Talbot TR, Johnson JG, Fergus C, Domenico JH, Schaffner W, Daniels TL, et al. Sustained improvement in hand hygiene adherence: utilizing shared accountability and financial incentives. Infect Control Hosp Epidemiol. 2015; 34:1129-36.

29. von Lengerke T, Ebadi E, Schock B, Krauth C, Lange K, Stahmeyer JT, et al. Impact of psychologically tailored hand hygiene interventions on nosocomial infections with multidrug-resistant organisms: results of the cluster-randomized controlled trial PSYGIENE. Antimicrob Resist Infect Control. 2019;8:56.

30. Aghdassi SJS, Schröder C, Gruhl D, Gastmeier P, Salm F. Point prevalence survey of peripheral venous catheter usage in a large tertiary care university hospital in Germany. Antimicrob Resist Infect Control. 2019;8:15.

\section{Publisher's Note}

Springer Nature remains neutral with regard to jurisdictional claims in published maps and institutional affiliations.

Ready to submit your research? Choose BMC and benefit from:

- fast, convenient online submission

- thorough peer review by experienced researchers in your field

- rapid publication on acceptance

- support for research data, including large and complex data types

- gold Open Access which fosters wider collaboration and increased citations

- maximum visibility for your research: over $100 \mathrm{M}$ website views per year

At $\mathrm{BMC}$, research is always in progress.

Learn more biomedcentral.com/submissions 